$11-2010$

\title{
Hemispheric Differences in Specificity Effects in Talker Identification
}

Julio Gonza'lez

University Jaume I

Teresa Cervera-Crespo

University of Valencia

Conor T. McLennan

Cleveland State University, c.mclennan@csuohio.edu

Follow this and additional works at: https://engagedscholarship.csuohio.edu/clpsych_facpub

Part of the Speech and Hearing Science Commons

How does access to this work benefit you? Let us know!

Publisher's Statement

(c) 2010 Springer Verlag

Recommended Citation

González, J., Cervera-Crespo, T., \& McLennan, C. T. (November 2010). Hemispheric differences in specificity effects in talker identification. Attention, Perception \& Psychophysics, 72, 8, 2265-73.

This Article is brought to you for free and open access by the Psychology Department at EngagedScholarship@CSU. It has been accepted for inclusion in Psychology Faculty Publications by an authorized administrator of EngagedScholarship@CSU. For more information, please contact library.es@csuohio.edu. 


\title{
Hemispheric differences in specificity effects in talker identification
}

\author{
JuLio GonZÁLEZ \\ University Jaume I, Castellón, Spain \\ Teresa Cervera-Crespo \\ University of Valencia, Valencia, Spain \\ AND \\ Conor T. MCLennan \\ Cleveland State University, Cleveland, Ohio
}

\begin{abstract}
In the visual domain, Marsolek and colleagues $(1999,2008)$ have found support for two dissociable and parallel neural subsystems underlying object and shape recognition: an abstract-category subsystem that operates more effectively in the left cerebral hemisphere (LH), and a specific-exemplar subsystem that operates more effectively in the right cerebral hemisphere (RH). Evidence of this asymmetry has been observed in priming specificity for linguistic (words, pseudoword forms) and nonlinguistic (objects) stimuli. In the auditory domain, the authors previously found hemispheric asymmetries in priming effects for linguistic (spoken words) and nonlinguistic (environmental sounds) stimuli. In the present study, the same asymmetrical pattern was observed in talker identification by means of two long-term repetition-priming experiments. Both experiments consisted of a familiarization phase and a final talker identification test phase, using sentences as stimuli. The results showed that specificity effects (an advantage for same-sentence priming, relative to different-sentence priming) emerged when the target stimuli were presented to the left ear $(\mathrm{RH})$, but not when the target stimuli were presented to the right ear ( $\mathrm{LH})$. Taken together, this consistent asymmetrical pattern of data from both domains — visual and auditory - may be indicative of a more general property of the human perceptual processing system. Theoretical implications are discussed.
\end{abstract}

In the visual domain, Marsolek and colleagues have hypothesized the existence of two dissociable and parallel neural subsystems involved in word form and object recognition: an abstract-category subsystem that operates more effectively in the left hemisphere (LH) and is less sensitive to the specific surface characteristics of stimuli, and a specific-exemplar subsystem that operates more effectively in the right hemisphere (RH) and is more sensitive to specific stimulus characteristics (Marsolek, 1999, 2003; Marsolek \& Burgund, 2008).

The strongest support for the two-systems hypothesis comes from studies in which the long-term repetitionpriming paradigm has been used. Priming refers to any facilitation in the processing of a stimulus as a consequence of encoding the same (or a highly related) stimulus in an earlier episode (Bowers, 1999). In this paradigm, participants are presented with a block of stimuli to which they must respond (the study phase). After a short distractor task, the participants are presented with another block of stimuli (the test phase), in which some of the stimuli from the first block are repeated. Typically, performance for repeated stimuli is better than performance for new (i.e., nonrepeated) stimuli. For example, in the lexical decision task, participants are typically faster and more accurate in categorizing letter strings as words when they were studied in an earlier phase of the experiment. However, if the first and second presentations (prime and target, respectively) mismatch on some dimension (e.g., letter case in visual words), the priming effect may be attenuated. This attenuation in priming is referred to as specificity (or a specificity effect).

Marsolek and colleagues have reported qualitatively distinct patterns of specificity in the two cerebral hemispheres: weak or no specificity in the LH and relatively more specificity in the RH. Evidence of this hemispheric asymmetry of specificity effects has been obtained in the recognition of familiar objects (Burgund \& Marsolek, 2000; Marsolek, 1999; Marsolek \& Burgund, 2003), word forms (Marsolek, 2004; Marsolek, Kosslyn, \& Squire, 1992; Marsolek, Schacter, \& Nicholas, 1996; Marsolek, Squire, Kosslyn, \& Lulenski, 1994; but see Koivisto, 1995), pseudoword forms (Burgund \& Marsolek, 1997), letter-like forms (Marsolek, 1995), and unfamiliar or novel objects (Marsolek \& Burgund, 2008).

J. González, gonzalez@psb.uji.es 
In the auditory domain, we recently found the same asymmetric pattern of specificity effects in the recognition of both spoken words (González \& McLennan, 2007) and environmental sounds (González \& McLennan, 2009). In the first study, we obtained hemispheric differences in talker specificity effects in spoken word recognition: The RH was more sensitive than the LH to surface information associated with talker identity during lexical perception. In particular, changing talkers between the first (study) and second (target) presentations of a spoken word affected performance in the RH (left ear), but not in the LH (right ear). This pattern was consistent across different tasks and experimental conditions. In the second study, we obtained specificity effects when environmental sounds were presented to the RH, but not when these same sounds were presented to the $\mathrm{LH}$. The procedure was as follows: We investigated exemplar specificity effects in four repetition priming experiments in which participants attempted to identify environmental sounds from initial 750 -msec sound stems. As was expected, repetition of an identical exemplar sound (e.g., the same bagpipe sound) resulted in more robust priming than did the repetition of a different exemplar sound (e.g., the sound of a different bagpipe). That is, the percentage of correct identification of the environmental source (a bagpipe) was higher in the identical-exemplar condition than in the differentexemplar condition. However, it is crucial to note that this advantage for same-exemplar priming, relative to different-exemplar priming (i.e., specificity), emerged only when the target stems were presented to the left ear $(\mathrm{RH})$, and not when presented to the right ear (LH).

Taken together, our data on the recognition of spoken words and environmental sounds, combined with Marsolek's data $(1994,1999,2000,2004)$ on visual word and visual object recognition, suggest that this pattern of results is perhaps indicative of a more general property of the human perceptual processing system, rather than being specific to any particular domain. An overall pattern across modalities is consistent with the idea that there may be two neural parallel subsystems, or processing styles, operating more effectively, although not necessarily exclusively, in each of the two hemispheres. This dual account could explain the apparent dilemma of why two objects (e.g., two different exemplars of pianos) are recognized as belonging to the same (abstract) category, but also to different (specific) categories (Marsolek, 1999). Moreover, several neuroimaging studies of auditory and visual priming have shown activity changes (reduction) in cortical areas involved in multimodal functions (Buckner, Koutstaal, Schacter, \& Rosen, 2000; Carlesimo et al., 2004; for a review, see Schacter, Dobbins, \& Schnyer, 2004), which supports the notion that there is some degree of cortical integration associated with priming through different sensory modalities.

We are interested in testing the extent to which this asymmetric pattern is a general feature of perception in the auditory domain. More specifically, the purpose of the present work is to study hemispheric differences in specificity effects (1) with a new type of stimulus and (2) when the processes that are involved differ from the processes that have been examined previously (González \& McLennan, 2007, 2009).

1. As was mentioned above, asymmetrical patterns of specificity have been observed in the perception of spoken words and environmental sounds; however, whether similar asymmetrical patterns of specificity would be obtained with other types of auditory stimuli, including voices, tones, noises, and music, remains an empirical question. The perception of voice or talker identity presents some properties quite different from other kinds of acoustic stimuli. Differences among talkers are perceived by processing the acoustical properties of indexical characteristics, which reflect both innate factors (anatomy of the vocal tract and resonant systems, age, gender, and so on) and learned (dialectal or idiolectal) aspects of speech (González \& Oliver, 2005; Kreiman, 1997; Remez, Fellowes, \& Nagel, 2007; Van Lancker, Kreiman, \& Emmorey, 1985). Neuropsychological (Kreiman \& Van Lancker, 1988; Van Lancker \& Canter, 1982; Van Lancker, Kreiman, \& Cummings, 1989) and neuroimaging (Belin \& Zatorre, 2003; Belin, Zatorre, \& Ahad, 2002; Von Kriegstein, Eger, Kleinschmidt, \& Giraud, 2003; Von Kriegstein, Smith, Patterson, Kiebel, \& Griffiths, 2010; see Belin, Fecteau, \& Bédard, 2004, for a review) evidence suggests that voice or talker perception abilities (hereafter referred to as talker identification) are predominantly realized in the right cerebral hemisphere. In the present study, we tested a more fine-grained hypothesis - specifically, whether hemispheric asymmetry exists for priming specificity during talker identification.

2. When attempting to identify spoken words (González \& McLennan, 2007) and familiar environmental sounds (González \& McLennan, 2009), listeners are able to access preexisting representations that are presumably quite stable and robust in their long-term memory (LTM) as a result of all of the previous encounters with tokens of the words and sounds throughout their lives. Recently, Marsolek and Burgund (2008) found the same asymmetric pattern in experiments using memory tasks with unfamiliar and novel objects viewed for the first and only time. In the present study, we used as stimuli voices belonging to talkers who were intentionally unknown to the participants; therefore, the listeners did not begin the experiment with preexisting representations of the identities of the talkers. Instead, a learning procedure was applied to these novel stimuli (Perrachione \& Wong, 2007a, 2007b), during which the participants presumably created representations for the identities of the talkers that allowed them to learn to recognize the talkers.

In particular, we carried out two experiments using the long-term repetition-priming paradigm to examine whether hemispheric differences would emerge when listeners were asked to identify talkers pronouncing a sentence. On the basis of previous findings, we expected an advantage (specificity) for same-sentence priming, relative to different-sentence priming. That is, the repetition of an identical sentence was expected to result in more robust priming for talker identification than would the pronunciation of a different sentence. However, the key point is whether a more pronounced same-sentence advantage 
would appear when the spoken sentences were presented to the left ear (RH), relative to when the spoken sentences were presented to the right ear (LH).

\section{EXPERIMENT 1}

\section{Method}

Participants. Thirty-two participants were recruited from the University of Valencia (Spain). They received partial credit for a course requirement. All the participants were right-handed (Edinburgh Handedness Inventory; Oldfield, 1971) native speakers of Spanish with no reported history of speech or hearing disorders.

Materials. The stimuli consisted of two Spanish sentences recorded from eight Spanish native speakers, four males and four females. The talkers had been students at the University Jaume I of Castellon (Spain) several years ago, and they were unknown to the participants. The ages of the talkers at the time of recording ranged from 22 to 29 years. The talkers had no reported history of speech or hearing disorders.

The two sentences were (1) "Procura mantener el aire limpio" ("Try to maintain clean air") and (2) " ¿Vienes mañana al estreno de la película?" ("Will you come tomorrow to the opening of the film?"). Both sentences were read by each of the talkers at a comfortable level and were recorded in a sound-attenuated booth on a Sony-TCD D-8 digital audiotape (DAT) recorder with a sampling frequency of $44.1 \mathrm{kHz}$, using a Shure SM58 microphone that was positioned at a distance of approximately $12 \mathrm{~cm}$ from the talker's mouth. The digital recordings were subsequently transferred to a personal computer and converted to 16-bit WAV files. Finally, the audio files were equated in root-mean-square (RMS) amplitude. Durations of the sound files ranged from 1,638 to $2,193 \mathrm{msec}(M=1,943 \mathrm{msec})$.

A 2,000-msec audio file was created containing pink noise. The noise was also digitized at a sampling frequency of $44.1 \mathrm{kHz}$ (16 bit), and the RMS amplitude was set to $3 \mathrm{~dB}$ below the level of the sentence files. Pink noise has a spectral frequency of $1 / f$ and is found mostly in nature. It was chosen (as in González \& McLennan, 2007) because its spectral level decreases with increasing frequency, as occurs in speech signals, and thus serves as an effective voice masker (and is also less annoying than white noise).

Procedure. The procedure closely followed that used by Perrachione and Wong (2007a, 2007b). The experiment consisted of a familiarization phase and a final talker identification test phase, and both phases were controlled by Inquisit 1.33 software on a Pentium PC. Before the experiment began, the participants were instructed that they would be learning to recognize four male and four female talkers by the sounds of their voices.

During the familiarization phase, the participants practiced identifying the talkers throughout the following five blocks of trials. (1) One male talker's name would appear on the screen while a recording of him saying a sentence was played bilaterally over the headphones. After the listener had heard the first male talker, the next male talker's name would appear while a recording of him reading the same sentence was played. After the listeners had heard all four male talkers in this way, they took a short quiz with feedback about the percentage of correct responses. During the quiz, all four male talkers' names would appear on the screen at the same time, while a sound file of one of them reading the sentence was played over the participants' headphones. The participants were instructed to identify which talker they believed was speaking by pressing a corresponding button on the computer keyboard. (2) The same procedure was followed for the four female talkers. (3) The first block was repeated, but now, during the quiz, the voice of each male talker was played twice, resulting in a total of 8 trials. (4) The second block was repeated, but now, during the quiz, the voice of each female talker was played twice, resulting in a total of 8 trials. (5) Finally, a quiz took place with the eight (four male and four female) talkers together. During this quiz the voice of each talker was played twice, resulting in a total of 16 trials. Overall, performance in the final block of training was .79.
After the familiarization phase, the participants performed a short distractor task, which consisted of completing the Edinburgh Handedness Inventory (Oldfield, 1971), before beginning the final talker identification test phase.

During the talker identification test phase, sentence stimuli (targets) were presented monaurally while the pink noise was presented simultaneously in the opposite ear. Half the target stimuli were presented to the left ear, and half were presented to the right ear, in random order. Note that because the majority of neural projections are contralateral (Kimura, 1967; Rosenzweig, 1951), a stimulus presented to the right ear should be processed more efficiently in the $\mathrm{LH}$, and vice versa. The identification phase consisted of a block similar to a practice quiz, except that no feedback was given. During this final test block, the voice of each of the eight (four male and four female) talkers was played once, in random order. Half of the stimuli used in the test phase were the same sentences (same-sentence priming condition) as those used during the familiarization phase, and half were different sentences that had not been heard during the familiarization phase (different-sentence priming condition). Half of the participants listened to Sentence A during the familiarization phase, followed by Sentences A (same) and B (different) during the test phase. The other half of the participants listened to Sentence B during the familiarization phase, followed by Sentences A (different) and $\mathrm{B}$ (same) during the test phase.

Design. The experimental design was an orthogonal combination of two levels of prime type (same sentence, different sentence) and two levels of ear of test presentation (left, right), resulting in four within-participants conditions. Four stimulus lists were created to ensure that each voice was assigned to every possible condition across participants. No participant heard more than one condition for a given voice during the test phase.

\section{Results}

Responses to the stimuli in the talker identification test phase were scored for accuracy. ${ }^{1} \mathrm{~A}$ two-way repeated measures ANOVA was performed with prime type (same sentence, different sentence) and ear of test presentation (left, right) as within-participants factors. Planned comparisons were performed in order to examine any possible difference between the same-sentence and different-sentence conditions for each ear (hemisphere). Separate analyses were carried out with participants $\left(F_{1}\right)$ and items $\left(F_{2}\right)$ as the random variables.

We found a significant main effect of prime type $\left[F_{1}(1,31)=9.89, M S_{\mathrm{e}}=0.087, p=.004, \eta_{\mathrm{p}}^{2}=.242\right.$; $\left.F_{2}(1,7)=6.36, M S_{\mathrm{e}}=0.033, p=.040, \eta_{\mathrm{p}}^{2}=.48\right]$, reflecting the higher accuracy performance in the same-sentence condition (.77) than in the different-sentence condition (.61). No other significant effects were obtained. Crucially (see Figure 1), planned comparisons demonstrated that the difference between the same-sentence and differentsentence conditions (.75 and .67 , respectively) was not significant when the targets were presented to the right ear $\left[F_{1}<1 ; F_{2}(1,7)=1.37, p=.280\right]$, but this difference was significant $(.80$ and .55$)$ when the targets were presented to the left ear $\left[F_{1}(1,31)=11.27, M S_{\mathrm{e}}=0.089\right.$, $p=.002, \eta_{\mathrm{p}}^{2}=.27 ; F_{2}(1,7)=7.35, M S_{\mathrm{e}}=0.034, p=$ $\left..030, \eta_{\mathrm{p}}^{2}=.51\right]$.

\section{Discussion}

The results of Experiment 1 on talker identification are consistent with predictions based on our previous results obtained in spoken word (González \& McLennan, 2007) and environmental sound (González \& McLennan, 2009) 


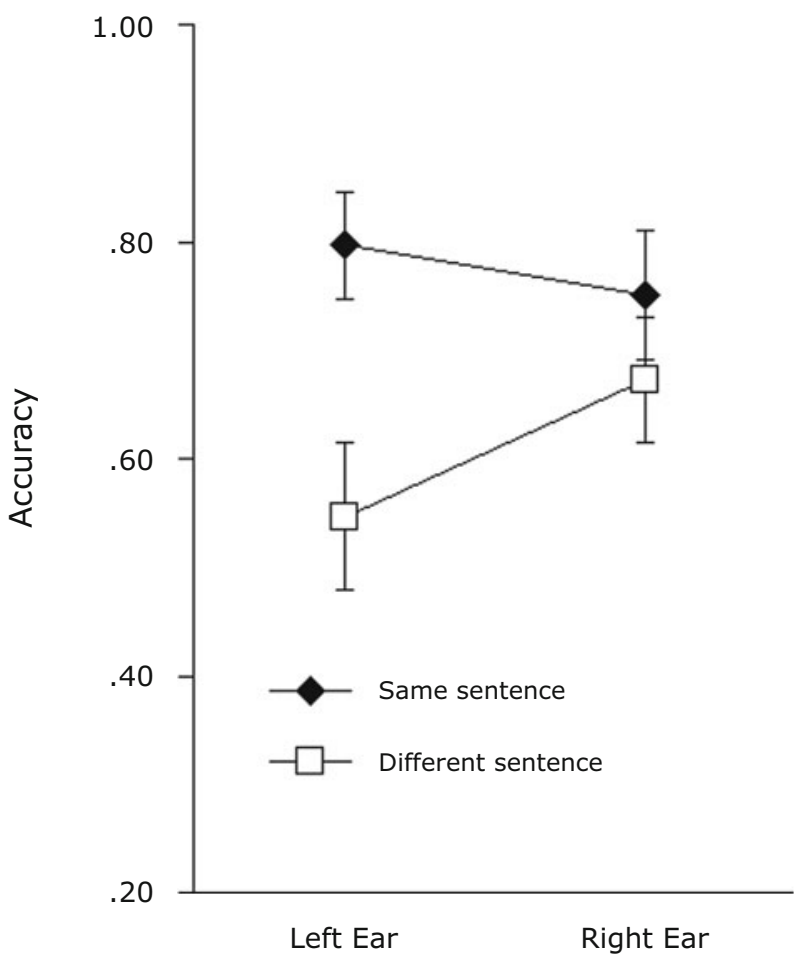

Figure 1. Experiment 1: Mean proportions of talker identification accuracy as a function of prime type and ear of target sentence presentation. Error bars indicate standard errors of the means.

recognition. In particular, specificity effects (an advantage for same-sentence priming, relative to different-sentence priming) emerged when the target stimuli were presented to the left ear (RH), but not when the target stimuli were presented to the right ear (LH).

Following the same procedure as in our previous studies on asymmetry of priming specificity (González \& McLennan, 2007, 2009), we presented pink noise to the ear opposite the ear that received each stimulus. The presentation of noise in the opposite ear should increase competition between the hemispheres, which, in turn, should increase the likelihood of observing hemispheric asymmetries (Fecteau, Enns, \& Kingstone, 2000; Kimura, 1961). Recent data provide evidence that presenting stimuli to one ear and noise to the other ear is an efficient strategy for examining hemispheric specialization in auditory cortical activity for both nonspeech (Behne, Scheich, \& Brechmann, 2005) and speech (Behne, Wendt, Scheich, \& Brechmann, 2006) stimuli. In order to test the robustness of this asymmetrical pattern in talker identification, we carried out an additional experiment under conditions less favorable to the emergence of hemispheric differences and more similar to natural conditions (i.e., conditions that would occur in daily life outside the laboratory). Specifically, we presented the sentence stimuli without presenting noise to the opposite ear. In our previous studies, the patterns were sufficiently robust that the asymmetic patterns emerged even when noise was not presented to the opposite ear, although the magnitude of the effects was not as large.

\section{EXPERIMENT 2}

In this experiment, we tested whether hemispheric asymmetry would still emerge under less favorable conditions for asymmetry - namely, without presenting noise to the opposite ear.

\section{Method}

Participants. Thirty-two new participants were recruited from the University of Valencia (Spain). They received partial credit for a course requirement. All the participants were right-handed (Edinburgh Handedness Inventory; Oldfield, 1971) native speakers of Spanish with no reported history of speech or hearing disorders. None of them had participated in Experiment 1.

Materials, Procedure, and Design. The materials, procedure, and design were identical to those in Experiment 1, with the following exception: During the talker identification test phase, noise was not presented in the ear opposite to the one receiving the sentence stimuli (targets). Overall, performance in the final block of training was .80.

\section{Results}

Responses to the stimuli in the talker identification test phase were scored for accuracy. Again, a two-way repeated measures ANOVA was performed, with prime type (same sentence, different sentence) and ear of test presentation (left, right) as within-participants factors. Planned comparisons were performed in order to examine any possible difference between the same-sentence and differentsentence conditions for each ear (hemisphere). Separate analyses were carried out with participants $\left(F_{1}\right)$ and items $\left(F_{2}\right)$ as the random variable.

We observed a significant main effect of prime type $\left[F_{1}(1,31)=6.82, M S_{\mathrm{e}}=0.064, p=.014, \eta_{\mathrm{p}}^{2}=.18 ;\right.$ $F_{2}(1,7)=4.45, M S_{\mathrm{e}}=0.024, p=.073(p=.037$, for a one-tailed test), $\eta_{\mathrm{p}}^{2}=.39$ ], reflecting the higher accuracy performance in the same-sentence condition (.78) than in the different-sentence condition (.66). No other significant effects were obtained. Crucially (see Figure 2), planned comparisons demonstrated that the difference between the same-sentence and different-sentence conditions (.77 and .72 , respectively) was not significant when the targets were presented to the right ear (both $F_{\mathrm{S}}<1$ ), but this difference was significant (.80 and .61) when the targets were presented to the left ear $\left[F_{1}(1,31)=5.94, M S_{\mathrm{e}}=\right.$ $0.095, p=.021, \eta_{\mathrm{p}}^{2}=.16 ; F_{2}(1,7)=4.09, M S_{\mathrm{e}}=0.033$, $p=.083$ ( $p=.042$, for a one-tailed test), $\eta_{\mathrm{p}}^{2}=.37$ ].

Comparing the data from Experiments 1 and 2, overall accuracy was nominally lower in Experiment 1 (.69) than in Experiment 2 (.72), but this difference did not approach statistical significance $(p=.530)$. Moreover, planned comparisons demonstrated that the lack of a statistical difference between the experiments occurred in both the same-sentence $(.77$ vs. .78; $p=.885)$ and the differentsentence (.61 vs. .66; $p=.410$ ) conditions, although the latter difference was nominally greater.

\section{Discussion}

Once again, we obtained the same general asymmetric pattern as that observed in Experiment 1, although the absence of noise in the opposite ear in Experiment 2 slightly decreased the asymmetry for specificity effects. 


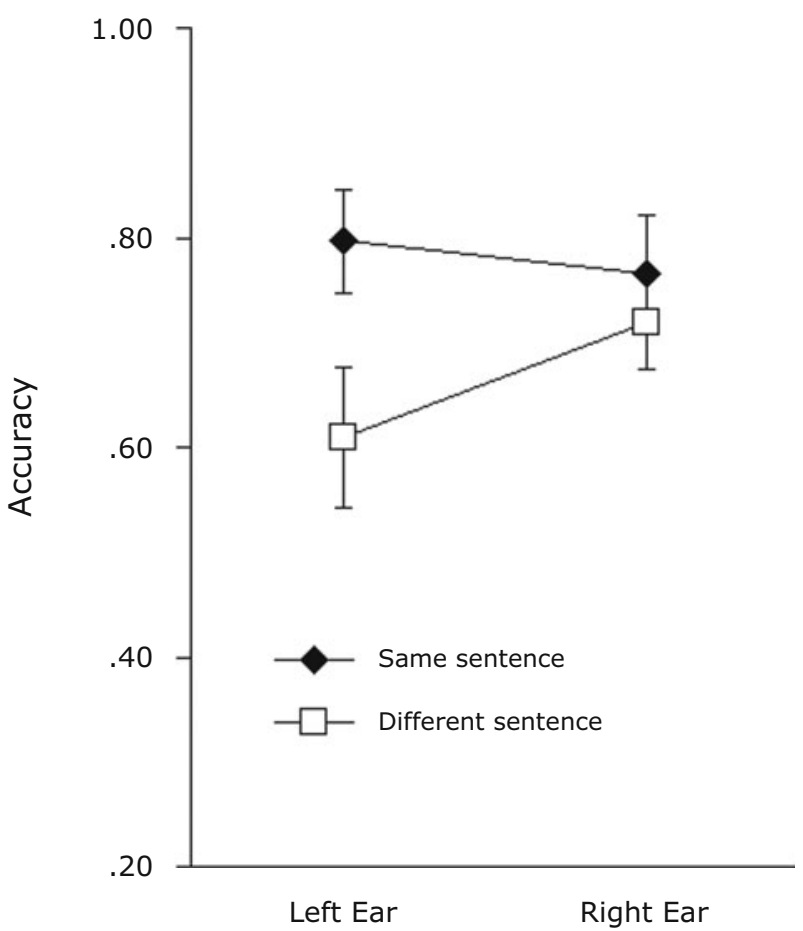

Figure 2. Experiment 2: Mean proportions of talker identification accuracy as a function of prime type and ear of target sentence presentation. Error bars indicate standard errors of the means.

\section{GENERAL DISCUSSION}

The main hypothesis under examination was that specificity effects in talker identification should be obtained when voices are presented to the left ear (RH), but not when presented to the right ear (LH). The results from Experiments 1 and 2 were consistent with this hypothesis. In the two long-term priming experiments, we observed specificity effects (an advantage for same-sentence priming, relative to different-sentence priming) when target sentences were presented to the left ear (RH), but not when they were presented to the right ear (LH).

This asymmetrical pattern is similar to the asymmetrical pattern observed in two previous studies of auditory perception, one on the perception of linguistic stimuli (spoken words; González \& McLennan, 2007) and one on the perception of nonlinguistic stimuli (environmental sounds; González \& McLennan, 2009). The first study showed hemispheric differences in specificity for spoken word recognition. In particular, changing talkers between the first and second presentations of a spoken word affected word recognition in the RH, but not in the LH. This pattern was consistent across different tasks and experimental conditions. In the second study, specificity effects were obtained when environmental sounds were presented to the RH, but not when presented to the LH. The experiments compared identification accuracy of environmental sounds under two priming conditions: repetition of an identical exemplar sound (e.g., the same bagpipe sound) or presentation of a different exemplar sound (e.g., the sound of a different bagpipe). As was expected, identicalexemplar repetition resulted in more robust priming than did different-exemplar presentation, but crucially, this advantage (specificity) occurred only when the test stimuli were presented to the left ear (RH), and not when presented to the right ear (LH). This pattern was consistent across four experiments with different tasks and experimental conditions.

The present study extends the investigation of hemispheric differences not only to a new class of stimuli (the recognition of talkers) that is quite different from other types of auditory stimuli, but also to a process that is different from previously explored processes. In González and McLennan (2007, 2009), cerebral assymetry emerged in the perception of stimuli quite familiar to the listeners (words in their native language, common environmental sounds). During processing, the listener matched the sensory input to stable, robust preexisting representations in their LTM as a consequence of their frequent encounters with these stimuli throughout their life. In the present study, the stimuli were the voices of unknown talkers, and thus the listeners lacked preexisting representations in their LTM. The task of identifying the talkers presumably required the listeners to use their working memory to create representations during the first phase of the experiment. Consequently, the nature of the processes involved in each of these situations (listening to familiar vs. unfamiliar stimuli) is different. Therefore, data from these previous studies, along with the present data, show that there are hemispheric differences in processing the surface characteristics of stimuli in the auditory perception of spoken words, environmental sounds, and voices: The RH seems to be more sensitive to stimulus-specific information than is the LH. This convergence of results across quite different auditory subdomains may be indicative of a general property of the auditory perceptual system.

Previous research has shown that speech and voice perception abilities are predominantly realized in the left and right cerebral hemispheres, respectively. One explanation for this speech/voice asymmetry is that the two hemispheres are specialized for processing different kinds of acoustic information. In particular, the LH may be specialized for processing temporal properties, and the RH may be specialized for processing spectral information (Zatorre \& Belin, 2001; Zatorre, Belin, \& Penhune, 2002). An alternative (although not necessarily mutually exclusive) explanation is based on the size of the temporal windows of analysis of the signal (Boemio, Fromm, Braun, \& Poeppel, 2005; Poeppel, 2003), such that the LH is specialized for processing smaller temporal windows of analysis, relative to the RH. However, some evidence suggests a functional integration between the speech and voice perception systems (Francis \& Driscoll, 2006; Perrachione, Pierrehumbert, \& Wong, 2009; Perrachione \& Wong, 2007b; Von Kriegstein et al., 2003; Von Kriegstein et al., 2010), such that the same acoustical information is asymmetrically processed depending on the nature of the task. For example, native speakers of Thai, but not of English, show a right ear (LH) advantage for Thai tones (Van Lancker \& Fromkin, 1973); a similar pattern is found 
for Mandarin tones (Wang, Jongman, \& Sereno, 2001). Francis and Driscoll observed that listeners who were trained to use small differences in voice onset time as a cue to talker identification showed a left ear (RH) advantage in that task. This processing shift from a typically LH acoustical cue to the RH suggests that lateralization may be driven by the functional demands, rather than always being driven by the properties of the acoustical stimulus. In the present study, we tested a more fine-grained hypothesis. Our question was not which hemisphere showed a better performance in a talker-identification task, but which hemisphere was more sensitive to a physical change of the stimulus in a talker identification task. Our results clearly indicate greater priming specificity in the RH. That is, the RH was more sensitive to a physical change in the stimulus (same vs. different sentence spoken by the same talker), whereas the LH was more immune to this change. This is the same pattern that we have observed in the recognition of spoken words (González \& McLennan, 2007) and environmental sounds (González \& McLennan, 2009), which points to a general property of auditory processing. This unequal sensitivity to variability in the surface features of the stimuli is obtained both when the task involves talker identification and when the task involves the perception of spoken words. In a sense, our previous work in spoken word recognition (González \& McLennan, 2007) and the present study are complementary. In the former, the listeners' task was to recognize the same words in the face of talker variability; in the latter, the listeners' task was to recognize the same talkers when the words varied. Despite these differences, the same pattern of increased sensitivity to stimulus variability in the RH emerged in both studies.

Furthermore, this asymmetrical pattern observed for priming specificity in the auditory domain is analogous to the asymmetrical pattern observed in recent years for priming specificity in visual perception. Using the visual half-field technique, Marsolek and colleagues have accumulated behavioral evidence about hemispheric differences in priming for a wide variety of visual stimuli: familiar objects (Burgund \& Marsolek, 2000; Marsolek, 1999; Marsolek \& Burgund, 2003), word forms (Marsolek, 2004; Marsolek et al., 1992; Marsolek et al., 1994; but see Koivisto, 1995), pseudoword forms (Burgund \& Marsolek, 1997), letter-like forms (Marsolek, 1995), and unfamiliar or novel objects (Marsolek \& Burgund, 2008). In these experiments, repetition priming appears attenuated if the first and second presentations of the same stimulus mismatch on some dimension (e.g., different font or case letter for words; different exemplar or depth orientation for objects), but crucially, this attenuation (i.e., specificity) emerges, or is greater, only when the stimuli are presented to the left visual field (RH). Marsolek and colleagues have accounted for many of these results by hypothesizing the existence of two dissociable and parallel neural subsystems: an abstract-category subsystem that operates more effectively in the LH and is less sensitive to specific surface characteristics of stimuli, and a specificexemplar subsystem that operates more effectively in the
RH and is more sensitive to specific stimulus characteristics (Marsolek, 1999; Marsolek \& Burgund, 2008).

Within the ongoing debate concerning the nature of the representations involved in object recognition, the dual framework challenges other contemporary object recognition theories based on a single and undifferentiated system involving either relatively abstract representations (Biederman, 1987; Hayworth \& Biederman, 2006; Wagemans, Van Gool, \& Lamote, 1996), relatively specific representations (Bülthoff \& Edelman, 1992; Tarr, Williams, Hayward, \& Gauthier, 1998), or both abstract and specific representations on a continuum within a single system (Farah, 1992; Hayward \& Williams, 2000). Beyond behavioral evidence, other data from neuropsychology (Beeri, Vakil, Adonsky, \& Levenkron, 2004; Farah, 1991), electrophysiology (Pickering \& Schweinberger, 2003), and fMRI (Garoff, Slotnik, \& Schacter, 2005; Koutstaal et al., 2001; Vuilleumier, Henson, Driver, \& Dolan, 2002; but see Chouinard, Morrissey, Köler, \& Goodale, 2008, and Large, Aldcroft, \& Vilis, 2007, for alternative interpretations) are consistent with a dual abstract-specific account. For example, in two event fMRI experiments, Vuilleumier et al. found that the repetition of different exemplars of visual objects with the same name (i.e., belonging to the same abstract category) affected only the left inferior frontal cortex. And crucially, priming-induced decreases in activity of the right fusiform cortex depended on whether 3-D objects were repeated with the same viewpoint, whereas left fusiform decreases were independent of the viewpoint. Koutstaal et al., using the same technique based on event fMRI, observed that neural correlates of priming indicated that the right fusiform cortex showed significantly less priming for repetition of different versus same exemplars than did the left fusiform.

Research on priming asymmetry in the auditory domain remains relatively scarce, but recent studies addressing this issue (González \& McLennan, 2007, 2009, and the present study) have obtained data consistent with the dual framework. Taken together, our data on the recognition of spoken words, environmental sounds, and talker identities-combined with the data on visual word and visual object and shape recognition - suggest that this multimodal convergence of results is perhaps indicative of a more general property of the human perceptual processing system, rather than specific to any particular domain. Neural correlates of priming - usually, reduction of activity - tend to show a cortical distribution not confined to a single sensorial modality. In this sense, several neuroimaging studies of within-modality auditory priming or visual priming show activity reduction in cortical areas involved in multimodal functions (Buckner et al., 2000; Carlesimo et al., 2004; for reviews, see Henson, 2003, and Schacter et al., 2004).

In the past few years, some interesting integrations have emerged across modalities. One example is the local-global processing distinction. Former data suggested a hemispheric specialization confined to the visual domain: Global or low spatial frequency information is preferentially processed in the $\mathrm{RH}$, and local or high spatial frequency information is 
preferentially processed in the LH (for a review, see Sanders \& Poeppel, 2007). New data from the auditory domain were consistent with the same pattern: Relatively slow auditory changes $(200-300 \mathrm{msec})$ are preferentially processed in the RH, whereas relatively fast changes $(25-50 \mathrm{msec})$ are preferentially processed in the LH (see Boemio et al., 2005). Given this transmodal convergence, the local-global distinction may define a general organizational principle that is compatible with a dual analytic-holistic account of lateralization (González \& McLennan, 2009).

Some authors have suggested that the widespread existence of specificity effects across several domains of priming implies that specificity has an adaptive value and might be associated with some type of cognitive resource conservation (Schacter et al., 2004). In a continuously changing environment, it is important to perform general (abstract) and specific categorizations about the objects and events in our surroundings, and such a requirement is not exclusive to one sensory (visual) modality. A dual categorization implies opposing capabilities. Neurocomputational simulations show that general and specific categorizations are performed more effectively by a dual model, particularly when abstract categories include both similar and dissimilar exemplars (see Marsolek, 2003). Network models with relatively scarce or less densely distributed patterns of activation favor a more feature-focused or analytic style of processing, where different units are sensitive to different features or portions of input patterns (O'Reilly \& Munakata, 2000; Rolls \& Milward, 2000; for a review, see Marsolek, 2003). Categorizations across quite different token stimuli are performed through discovering which features are almost always present in the inputs belonging to a particular category (presence-diagnostic features), which features are almost always absent for that category (absence-diagnostic features), and which features sometimes are and other times are not present for that category (nondiagnostic features) (Marsolek, 2003). Here, features correspond to a relatively small number of simple portions of whole input patterns, because little information is common to the dissimilar exemplars. On the contrary, less scarce, or more densely distributed, patterns of activation favor a more holistic processing style in which extremely specific information is represented (Ballard, 1986; Hinton, McClelland, \& Rumelhart, 1986; Marsolek \& Burgund, 1997). Here, the diagnostic information for distinguishing similar exemplars corresponds to a large number of relatively complex features of whole input stimuli, because so much information is common to the similar exemplars. Because a single and unified system cannot represent both sparsely and densely distributed activations, dissociable subsystems may be the best way to accomplish these opposing processing styles (Marsolek, 2003).

Finally, future work examining hemispheric differences in specificity effects in the identification of famous talkers will provide a more complete picture regarding how listeners represent and process spoken sounds, including a better understanding of the role that listeners' previous familiarity with the sounds plays in studies examining hemispheric differences. On the other hand, if a dual abstract-specific theory characterizes auditory processing, further research should also explore priming asymmetries in other subdomains of auditory perception, including music, noise, and abstract synthetic sounds. From a broader theoretical point of view, if a dual and asymmetrical framework accounts for perceptual processing beyond a particular modality, future work should shed new light on potential hemispheric asymmetries in the remaining sensory modalities (touch, taste, and smell) to determine, for example, whether greater specificity will be obtained when objects are tactilely recognized with the left hand $(\mathrm{RH})$ rather than with the right hand (LH).

\section{AUTHOR NOTE}

This research was supported in part by BRAINGLOT, a Spanish Research Network on Bilingualism and Cognitive Neuroscience (Consolider-Ingenio 2010 Scheme, Spanish Ministry of Science and Education), by Research Grant PSI 2009-10067 (Ministry of Science and Technology of Spain), and by Research Grant R03 DC 007316 from the National Institute on Deafness and Other Communication Disorders, National Institutes of Health. The authors thank Lynne Nygaard (action editor of $A P \& P$ ), Pascal Belin, and two anonymous reviewers for their helpful feedback on an earlier version of the manuscript. Correspondence concerning this article should be addressed to J. González, Dpt. Psicología Básica, Clínica y Psicobiología, Universitat Jaume I, 12071-Castellón de la Plana, Spain (e-mail: gonzalez@psb.uji.es).

\section{REFERENCES}

BALLARD, D. H. (1986). Cortical connections and parallel processing: Structure and function. Behavioral \& Brain Sciences, 9, 67-120. doi:10.1017/S0140525X00021555

Beeri, M. S., Vakil, E., Adonsky, A., \& Levenkron, S. (2004). The role of the cerebral hemispheres in specific versus abstract priming. Laterality, 9, 313-323. doi:10.1080/13576500342000176

Behne, N., Scheich, H., \& Brechmann, A. (2005). Contralateral white noise selectively changes right human auditory cortex activity caused by a FM-direction task. Journal of Neurophysiology, 93, 414-423. doi:10.1152/jn.00568.2004

Behne, N., Wendt, B., Scheich, H., \& Brechmann, A. (2006). Contralateral white noise selectively changes left human auditory cortex activity in a lexical decision task. Journal of Neurophysiology, 95, 2630-2637. doi:10.1152/jn.01201.2005

Belin, P., Fecteau, S., \& Bédard, C. (2004). Thinking the voice: Neural correlates of voice perception. Trends in Cognitive Sciences, $\mathbf{3}$, 129-135. doi:10.1016/j.tics.2004.01.008

BeLIN, P., \& ZATORRE, R. J. (2003). Adaptation to speaker's voice in right anterior temporal lobe. NeuroReport, 14, 2105-2109. doi:10.1097/ 00001756-200311140-00019

Belin, P., Zatorre, R. J., \& Ahad, P. (2002). Human temporal-lobe response to vocal sounds. Cognitive Brain Research, 13, 17-26. doi:10 .1016/S0926-6410(01)00084-2

Biederman, L. (1987). Recognition-by-components: A theory of human image understanding. Psychological Review, 94, 115-147. doi:10 .1037/0033-295X.94.2.115

Boemio, A., Fromm, S., Braun, A., \& Poeppel, D. (2005). Hierarchical and asymmetric temporal sensitivity in human auditory cortices. Nature Neuroscience, 8, 389-395. doi:10.1038/nn1409

Bowers, J. S. (1999). Priming is not all bias: Commentary on Ratcliff and McKoon (1997). Psychological Review, 106, 582-596. doi:10.1037/0033-295X.106.3.582

Buckner, R. L., Koutstaal, W., Schacter, D. L., \& Rosen, B. R. (2000). Functional MRI evidence for a role of frontal and inferior temporal cortex in amodal components of priming. Brain, 123, 620640. doi:10.1093/brain/123.3.620

Bülthoff, H. H., \& Edelman, S. (1992). Psychophysical support for a two-dimensional view interpolation theory of object recognition. Proceedings of the National Academy of Sciences, 89, 60-64.

Burgund, E. D., \& Marsolek, C. J. (1997). Letter-case-specific prim- 
ing in the right cerebral hemisphere with a form-specific perceptual identification task. Brain \& Cognition, 35, 239-258. doi:10.1006/ brcg.1997.0940

Burgund, E. D., \& MarsoleK, C. J. (2000). Viewpoint-invariant and viewpoint-dependent object recognition in dissociable neural subsystems. Psychonomic Bulletin \& Review, 7, 480-489.

Carlesimo, G. A., Turriziani, P., Paulesu, E., Gorini, A., Caltagirone, C., Fazio, F., \& Perani, D. (2004). Brain activity during intra- and cross-modal priming: New empirical data and review of the literature. Neuropsychologia, 42, 14-24. doi:10.1016/S0028 -3932(03)00148-9

Chouinard, P. A., Morrissey, B. F., Köler, S., \& Goodale, M. A. (2008). Repetition suppression in occipital-temporal visual areas is modulated by physical rather than semantic features of objects. NeuroImage, 41, 130-144. doi:10.1016/j.neuroimage.2008.02.011

FARAH, M. J. (1991). Patterns of co-occurrence among the associative agnosias: Implications for visual object representation. Cognitive Neuropsychology, 8, 1-19. doi:10.1080/02643299108253364

FARAH, M. J. (1992). Is an object an object an object? Cognitive and neuropsychological investigations of domain specificity in visual object recognition. Current Directions in Psychological Science, 1, 164-169. doi:10.1111/1467-8721.ep11510333

Fecteau, J. H., Enns, J. T., \& Kingstone, A. (2000). Competitioninduced visual field differences in search. Psychological Science, 11, 386-393. doi:10.1111/1467-9280.00275

Fellowes, J. M., Remez, R. E., \& Rubin, P. E. (1997). Perceiving the sex and identity of a talker without natural vocal timbre. Perception \& Psychophysics, 59, 839-849.

Francis, A. L., \& Driscoll, C. (2006). Training to use voice onset time as a cue to talker identification induces a left-ear/right-hemisphere processing advantage. Brain \& Language, 98, 310-318. doi:10.1016/ j.bandl.2006.06.002

Garoff, R. J., Slotnick, S. D., \& Schacter, D. L. (2005). The neural origins of specific and general memory: The role of the fusiform cortex. Neuropsychologia, 43, 847-859. doi:10.1016/j .neuropsychologia.2004.09.014

González, J., \& McLennan, C. T. (2007). Hemispheric differences in indexical specificity effects in spoken word recognition. Journal of Experimental Psychology: Human Perception \& Performance, 33, 410-424. doi:10.1037/0096-1523.33.2.410

GonZÁlez, J., \& McLennan, C. T. (2009). Hemispheric differences in the recognition of environmental sounds. Psychological Science, 20, 887-894. doi:10.1111/j.1467-9280.2009.02379.x

GonZÁlez, J., \& Oliver, J. C. (2005). Gender and speaker identification as a function of the number of channels in spectrally reduced speech. Journal of the Acoustical Society of America, 118, 461-470. doi:10.1121/1.1928892

Hayward, W. G., \& Williams, P. (2000). Viewpoint dependence and object discriminability. Psychological Science, 11, 7-12. doi:10.1111/ $1467-9280.00207$

Hayworth, K. J., \& Biederman, I. (2006). Neural evidence for intermediate representations in object recognition. Vision Research, 46, 4024-4031. doi:10.1016/j.visres.2006.07.015

Henson, R. N. A. (2003). Neuroimaging studies of priming. Progress in Neurobiology, 70, 53-81. doi:10.1016/S0301-0082(03)00086-8

Hinton, G. E., McClelland, J. L., \& Rumelhart, D. E. (1986). Distributed representations. In D. E. Rumelhart \& J. L. McClelland (Eds.), Parallel distributed processing: Explorations in the microstructure of cognition. Vol. 1: Foundations (pp. 282-317). Cambridge, MA: MIT Press.

KimuRA, D. (1961). Cerebral dominance and the perception of verbal stimuli. Canadian Journal of Psychology, 15, 166-171. doi:10.1037/ h0083219

KimURA, D. (1967). Functional asymmetry of the brain in dichotic listening. Cortex, 3, 163-178.

KoIvisto, M. (1995). On functional brain asymmetries in perceptual priming. Brain \& Cognition, 29, 36-53. doi:10.1006/brcg.1995.1266

Koutstaal, W., Wagner, A. D., Rotte, M., Maril, A., Buckner, R. L., \& SCHACTER, D. L. (2001). Perceptual specificity in visual object priming: Functional magnetic resonance imaging evidence for a laterality difference in fusiform cortex. Neuropsychologia, 39, 184199. doi:10.1016/S0028-3932(00)00087-7
Kreiman, J. (1997). Listening to voices: Theory and practice in voice perception research. In K. Johnson \& J. W. Mullennix (Eds.), Talker variability in speech processing (pp. 85-108). San Diego: Academic Press.

Kreiman, J., \& Van LancKer, D. (1988). Hemispheric specialization for voice recognition: Evidence from dichotic listening. Brain \& Language, 34, 246-252. doi:10.1016/0093-934X(88)90136-8

LARGE, M. E., AldCroft, A., \& Vilis, T. (2007). Task-related laterality effects in the lateral occipital complex. Brain Research, 1128, 130138. doi:10.1016/j.brainres.2006.10.023

MarsoleK, C. J. (1995). Abstract visual-form representations in the left cerebral hemisphere. Journal of Experimental Psychology: Human Perception \& Performance, 21, 375-386. doi:10.1037/0096 $-1523.21 .2 .375$

Marsolek, C. J. (1999). Dissociable neural subsystems underlie abstract and specific object recognition. Psychological Science, 10, 111118. doi:10.1111/1467-9280.00117

MarsoleK, C. J. (2003). What is priming and why? In J. S. Bowers \& C. J. Marsolek (Eds.), Rethinking implicit memory (pp. 41-64). Oxford: Oxford University Press.

MarsoleK, C. J. (2004). Abstractionist versus exemplar-based theories of visual word priming: A subsystems resolution. Quarterly Journal of Experimental Psychology, 57A, 1233-1259. doi:10.1080/ 02724980343000747

Marsolek, C. J., \& Burgund, E. D. (1997). Computational analyses and hemispheric asymmetries in visual-form recognition. In S. Christman (Ed.), Cerebral asymmetries in sensory and perceptual processing (pp. 125-158). Amsterdam: Elsevier.

Marsolek, C. J., \& Burgund, E. D. (2003). Visual recognition and priming of incomplete objects: The influence of stimulus and task demands. In J. S. Bowers \& C. J. Marsolek (Eds.), Rethinking implicit memory (pp. 139-156). Oxford: Oxford University Press.

Marsolek, C. J., \& Burgund, E. D. (2008). Dissociable neural subsystems underlie visual working memory for abstract categories and specific exemplars. Cognitive, Affective, \& Behavioral Neuroscience, 8, 17-24. doi:10.3758/CABN.8.1.17

Marsolek, C. J., Kosslyn, S. M., \& Souire, L. R. (1992). Formspecific visual priming in the right cerebral hemisphere. Journal of Experimental Psychology: Learning, Memory, \& Cognition, 18, 492508. doi: $10.1037 / 0278-7393.18 .3 .492$

Marsolek, C. J., Schacter, D. L., \& Nicholas, C. D. (1996). Formspecific visual priming for new associations in the right cerebral hemisphere. Memory \& Cognition, 24, 539-556.

Marsolek, C. J., Souire, L. R., Kosslyn, S. M., \& Lulenski, M. E. (1994). Form-specific explicit and implicit memory in the right cerebral hemisphere. Neuropsychology, 8, 588-597. doi:10.1037/0894 $-4105.8 .4 .588$

OLDFIELD, R. C. (1971). The assessment and analysis of handedness: The Edinburgh inventory. Neuropsychologia, 9, 97-113. doi:10.1016/ 0028-3932(71)90067-4

O'Reilly, R. C., \& Munakata, Y. (2000). Computational explorations in cognitive neuroscience. Cambridge, MA: MIT Press.

Perrachione, T. K., Pierrehumbert, J. B., \& Wong, C. M. (2009). Differential neural contributions to native- and foreign-language talker identification. Journal of Experimental Psychology: Human Perception \& Performance, 35, 1950-1960. doi:10.1037/a0015869

Perrachione, T. K., \& Wong, P. C. M. (2007a, August). Increased lefthemisphere contribution to native-versus foreign-language talker identification revealed by dichotic listening. Poster presented at the 16th Meeting of the International Congress of Phonetic Sciences, Saarbrücken, Germany.

Perrachione, T. K., \& Wong, P. C. M. (2007b). Learning to recognize speakers of a non-native language: Implications for the functional organization of human auditory cortex. Neuropsychologia, 45, 18991910. doi:10.1016/j.neuropsychologia.2006.11.015

Pickering, E. C., \& Schweinberger, S. R. (2003). N200, N250r, and N400 event-related brain potentials reveal three loci of repetition priming for familiar names. Journal of Experimental Psychology: Learning, Memory, \& Cognition, 29, 1298-1311. doi:10.1037/0278 $-7393.29 .6 .1298$

Poeppel, D. (2003). The analysis of speech in different temporal integration windows: Cerebral lateralization as asymmetric sampling 
in time. Speech Communication, 41, 245-255. doi:10.1016/S0167 $-6393(02) 00107-3$

Remez, R. E., Fellowes, J. M., \& Nagel, D. S. (2007). On the perception of similarity among talkers. Journal of the Acoustical Society of America, 122, 3688-3696. doi:10.1121/1.2799903

Remez, R. E., Fellowes, J. M., \& Rubin, P. E. (1997). Talker identification based on phonetic information. Journal of Experimental Psychology: Human Perception \& Performance, 23, 651-666. doi:10.1037/0096-1523.23.3.651

RolLs, E. T., \& MilWaRd, T. (2000). A model of invariant object recognition in the visual system: Learning rules, activation functions, lateral inhibition, and information-based performance measures. Neural Computation, 12, 2547-2572. doi:10.1162/089976600300014845

RosenZweIG, M. R. (1951). Representation of the two ears at the auditory cortex. American Journal of Physiology, 167, 147-158.

SANDERS, L., \& PoEPPEL, D. (2007). Local and global auditory processing: Behavioral and ERP evidence. Neuropsychologia , 45, 1172-1186. doi:10.1016/j.neuropsychologia.2006.10.010

Schacter, D. L., Dobbins, I. G., \& Schnyer, D. M. (2004). Specificity of priming: A cognitive neuroscience perspective. Nature Reviews Neuroscience, 5, 853-862. doi:10.1038/nrn1534

Sheffert, S. M., Fellowes, J. M., Pisoni, D. B., \& Remez, R. E. (2002). Learning to recognize talkers from natural, sinewave, and reversed speech samples. Journal of Experimental Psychology: Human Perception \& Performance, 28, 1447-1469. doi:10.1037/0096 $-1523.28 .6 .1447$

Tarr, M. J., Williams, P., Hayward, W. G., \& Gauthier, I. (1998). Three-dimensional object recognition is viewpoint dependent. Nature Neuroscience, 1, 275-277. doi:10.1038/1089

VAN LANCKer, D., \& CANTER, G. J. (1982). Impairment of voice and face recognition in patients with hemispheric damage. Brain \& Cognition, 1, 185-195. doi:10.1016/0278-2626(82)90016-1

Van LancKer, D., \& Fromkin, V. A. (1973). Hemispheric specialization for pitch and "tone": Evidence from Thai. Journal of Phonetics, 1, 101-109.

Van Lancker, D., Kreiman, J., \& Cummings, J. (1989). Voice perception deficits: Neuroanatomical correlates of phonagnosia. Journal of Clinical Experimental Neuropsychology, 11, 665-674. doi:10.1080/01688638908400923

Van Lancker, D., Kreiman, J., \& Emmorey, K. (1985). Familiar voice recognition: Patterns and parameters. Part I: Recognition of backward voices. Journal of Phonetics, 13, 19-38.

Von Kriegstein, K., Eger, E., Kleinschmidt, A., \& Giraud, A. L. (2003). Modulation of neural responses to speech by directing atten- tion to voices or verbal content. Cognitive Brain Research, 17, 48-55. doi:10.1016/S0926-6410(03)00079-X

Von Kriegstein, K., Smith, D. R., Patterson, R. D., Kiebel, S. J., \& GRIFFITHS, T. D. (2010). How the human brain recognizes speech in the context of changing speakers. Journal of Neuroscience, 30, 629638. doi:10.1523/JNEUROSCI.2742-09.2010

Vuilleumier, P., Henson, R. N., Driver, J., \& Dolan, R. J. (2002). Multiple levels of visual object constancy revealed by event-related fMRI of repetition priming. Nature Neuroscience, 5, 491-499. doi:10.1038/nn839

Wagemans, T. D., Van Gool, L., \& Lamote, C. (1996). The visual system's measurement of invariants need not itself be invariant Psychological Science, 7, 232-236. doi:10.1111/j.1467-9280.1996 .tb00365.X

Wang, Y., Jongman, A., \& Sereno, J. A. (2001). Dichotic perception of Mandarin tones by Chinese and American listeners. Brain \& Language, 78, 332-348. doi:10.1006/brln.2001.2474

ZATORRE, R. J., \& Belin, P. (2001). Spectral and temporal processing in human auditory cortex. Cerebral Cortex, 11, 946-953. doi:10.1093/ cercor/11.10.946

Zatorre, R. J., Belin, P., \& Penhune, V. B. (2002). Structure and function of auditory cortex: Music and speech. Trends in Cognitive Sciences, 6, 37-46. doi:10.1016/S1364-6613(00)01816-7

\section{NOTES}

1. RTs were not measured because the response consisted of pressing one key among eight possible keys (one for each talker), so this would not be an online measure of the processes under investigation. In the present study, the main dependent variable was accuracy, which is typical of many identification experiments with several possible responses, including both our own previous work on environmental sound recognition (González \& McLennan, 2007) and other studies on talker identification (e.g., Fellowes, Remez, \& Rubin, 1997; Perrachione, Pierrehumbert, \& Wong, 2009; Perrachione \& Wong, 2007a, 2007b; Remez, Fellowes, \& Rubin, 1997; Sheffert, Fellowes, Pisoni, \& Remez, 2002).

2. Partial eta-squared $\left(\eta_{\mathrm{p}}^{2}\right)$ refers to the proportion of variability in the dependent measure that is attributable to a factor. The effect size interpretations for $\eta_{\mathrm{p}}^{2}$ values are as follows: $.01=$ small, $.06=$ medium, and $.14=$ large. 